\title{
Bisphosphonate Treatment Modifies Canine Bone Mineral and Matrix Properties and their Heterogeneity
}

\author{
Samuel Gourion-Arsiquaud ${ }^{1}$, Matthew R. Allen ${ }^{2}$, David B. Burr ${ }^{2}$, Deepak Vashishth ${ }^{3}$, Simon \\ Y. Tang ${ }^{3}$, and Adele L. Boskey ${ }^{1}$ \\ ${ }^{1}$ Hospital for Special Surgery, New York, NY, USA \\ 2 Indiana University School of Medicine, Indianapolis, IN, USA \\ ${ }^{3}$ Rensselaer Polytechnic Institute, Troy, NY
}

\section{Abstract}

Bone loss and alterations in bone quality are major causes leading to bone fragility in postmenopausal women. Although bisphosphonates are well known to reduce bone turnover and prevent bone loss in postmenopausal osteoporosis, their effects on other bone properties are not fully characterized. Changes in bone mineral and matrix properties may contribute to the anti-fracture efficacy observed with bisphosphonate treatments. The aim of this work was to analyze the effect of a one-year treatment with either alendronate or risedronate, at low and high doses, on spatially resolved bone material and compositional properties that could contribute to the fracture efficacy of these agents.

Distal tibias from thirty normal beagles that had been treated daily for one year with oral doses of vehicle (Veh), alendronate (Aln) at 0.2 or $1 \mathrm{mg} / \mathrm{kg}$, and risedronate (Ris) at $0.1 \mathrm{or} 0.5 \mathrm{mg} / \mathrm{kg}$ were analyzed by Fourier Transform Infrared imaging (FTIRI) to assess the changes in both mineral and matrix properties in discrete bone areas. The widths at half maximum of the pixel histograms for each FTIRI parameter were used to assess the heterogeneity of the bone tissue.

Aln and Ris increased the mineral content and the collagen maturity mainly in cancellous bone and at the endocortical surface. Significant differences were observed in the mineral content and in the hydroxyapatite crystallinity distribution in bone tissue, which can contribute to reduced ductility and micro-crack accumulation. No significant differences were observed between low and high dose nor between Aln and Ris treatments.

These results show that pharmacologic suppression of bone turnover increases the mineral and matrix bone tissue maturity in normal cancellous and endocortical bone areas where bone turnover is higher. These positive effects for decreased fracture risk are also associated with a loss of bone heterogeneity that could be one factor contributing to increased bone tissue brittleness and micro-crack accumulation.

\footnotetext{
(c) 2009 Elsevier Inc. All rights reserved.

Address for Correspondence: Adele L Boskey Hospital for Special Surgery 535 E $70^{\text {th }}$ Street New York, NY 10021 FAX 2124725331 Phone 2126061453 Boskeya @ hss.edu.

Samuel Gourion-Arsiquaud gourions@ hss.edu Matthew R. Allen matallen@iupui.edu David B. Burr dburr@iupui.edu Deepak Vashisth vashid@ rpi.edu Simon Y. Tang tangsy@ orthosurg.ucsf.edu

Publisher's Disclaimer: This is a PDF file of an unedited manuscript that has been accepted for publication. As a service to our customers we are providing this early version of the manuscript. The manuscript will undergo copyediting, typesetting, and review of the resulting proof before it is published in its final citable form. Please note that during the production process errors may be discovered which could affect the content, and all legal disclaimers that apply to the journal pertain.
}

None of the authors has a conflict to declare. 


\section{Keywords}

Bisphosphonate; bone remodeling; FTIR imaging; bone heterogeneity; osteoporosis

\section{Introduction}

The fragility of bone is determined by the quantity of bone present, usually measured in terms of bone mass, or bone mineral density (BMD), and also by the quality of the bone. Bone quality refers to the bone composition and structure that contribute to bone strength independent of BMD. Bone quality may include bone microarchitecture, mineralization, mineral and matrix composition, and the distribution of micro-cracks [1-7]. Although it is well-accepted that mineral and matrix bone properties contribute to bone's fracture resistance, their precise effect on bone mechanical properties remains unknown. While several studies have shown efficacy of anti-resorptive agents like alendronate (Aln) and risedronate (Ris) in preventing bone fragility in postmenopausal osteoporosis and other metabolic bone diseases and in metastatic bone cancer by increasing BMD [8-15], the observed changes in BMD following bisphosphonate treatment are not sufficient to explain the reduction in fracture risk in these patients [16]. Indeed, an increase in BMD is not necessarily associated with a reduction of fracture risk, as shown by the BMD increases with the fluoride therapy [17]. Other compositional and structural factors independent of BMD alter bone quality and could be associated with fracture reduction [18]. These factors have to be analyzed to fully understand the mechanisms for the benefit of bisphosphonate treatment and its effects on the bone tissue properties.

Mineral content and collagen matrix structure contribute significantly to mechanical bone properties and fracture resistance $[5,7,18]$. The bone organic matrix is predominantly type I collagen. Following secretion from the cell, collagen undergoes numerous post-translational modifications which play an important role in matrix mineralization, and with time the collagen is stabilized by a cross-linking network $[18,19]$. The mineralization process consists of primary mineral deposition in the collagen matrix scaffold followed by a slow and progressive mineral deposition called secondary mineralization. With aging, tissue mineralization, collagen maturity, and collagen cross-linking increase [20-23]. These changes tend to stabilize the collagen network, increasing stiffness but also reducing the ductility of the tissue $[5,19,24]$.

In humans, bisphosphonates reduce fracture risk in osteoporotic women and men [10,11,25, 26] by suppressing bone turnover through inhibition of osteoclast-mediated resorption [27]. In this way, they slow the rate of bone loss and increase the BMD [9]. Recently it was also found that the bisphosphonates induced differences in the maturation profile of collagen $[18,28]$. A study using FTIR imaging (FTIRI), a technique that analyzes the compositional changes in bone tissue with $\sim 7 \mu \mathrm{m}$ spatial resolution, showed the cortical bone was more mineralized in Aln-treated postmenopausal iliac crest compared to the placebo [29] but found no significant changes in collagen maturity. A decrease in the variation (heterogeneity) of all of the measured FTIRI parameters including collagen maturity was also noted with Aln treatment. This led us to posit that bisphosphonate treatment, in addition to aging and osteoporosis, narrowed the heterogeneity of numerous tissue-level parameters. To address the effects of bisphosphonates on these properties, independent of aging and osteoporosis, we chose to study tissue from nonovariectomized bisphosphonate-treated and control dogs.

In the dog model, studies using biochemical analyses reported that bisphosphonates significantly alter the organic matrix by increasing collagen maturity [30,31]. A one-year treatment of Ris or Aln, at doses at or above those used for treatment of osteoporosis, suppressed bone remodeling, and increased mineral content and vertebral stiffness [32-34]. These doses 
not only affect the mineral fraction of bone, but also significantly increased collagen crosslinking (both enzymatic and non-enzymatic types) and collagen isomerization [30]. On the other hand this remodeling suppression also significantly increased micro-damage accumulation and decreased some mechanical properties in dog bones [35-38]. Although FTIRI is a useful tool to assess changes in mineralization or collagen cross-link maturity in bone tissue [23] no modifications were observed in cortical bone from dogs treated with high doses of bisphosphonates [33].

Lack of agreement between chemical and spectroscopic measurements of collagen maturity and between data in osteoporotic humans $[29,39]$ and within the non-osteoporotic preclinical models led us to hypothesize that these differences, in addition to being related to the initial status of the bone (osteoporotic or normal), were species, site, drug, and technique dependent. To address this hypothesis this study used FTIRI to compare the spatial variation of mineral and matrix properties in response to suppression of remodeling caused by one-year treatment of normal dogs with either alendronate or risedronate in specific bone areas.

\section{Materials and Methods}

Tibias from thirty female beagles (average age at sacrifice $2.3 \pm 0.02$ years) used in a previous experiment [34] were cleaned of soft tissue. The dogs had been purchased from Marshall Farms USA (North Rose, NY), acclimated for a period of 1 month, housed two per cage in environmentally controlled rooms, and fed standard dog chow. Water was available at all times. Drug administration was done approximately $2 \mathrm{~h}$ before feeding. All procedures were in accordance with approved NIH guidelines, under a protocol approved by the Indiana University School of Medicine Animal Care and Use Committee. The dogs had been assigned to treatment groups ( $n=6$ /group) by matching body weights. All dogs were treated daily for 1 year with oral doses of vehicle (Veh), risedronate (Ris, 0.1 or $0.5 \mathrm{mg} / \mathrm{kg} / \mathrm{day}$; Procter and Gamble Pharmaceuticals), or alendronate (Aln, 0.2 or $1 \mathrm{mg} / \mathrm{kg} / \mathrm{day}$; Merck). Doses of each bisphosphonate for the high-dose group were 5-6 times greater, calculated on a $\mathrm{mg} / \mathrm{kg}$ basis, than the clinical doses used for osteoporosis treatment in humans. At the end of the experiment, dogs were killed by an overdose of a sodium pentobarbital derivative $(0.22 \mathrm{mg} / \mathrm{kg}$ intravenously, Beuthanasia-D Special; Schering-Plough Animal Health Care Co., Kenilworth, $\mathrm{NJ})$.

Tibias were fixed in alcohol and embedded in polymethylmethacrylate (PMMA). They were cut at 2-3 microns thickness and mounted on barium fluoride infrared windows (SpectraTech, Hopewell Junction, NY). The undecalcified sections were examined using a Perkin Elmer Spotlight 300 Infrared Imaging system (Perkin Elmer Instruments, Waltham, MA, USA) at a spectral resolution of $4 \mathrm{~cm}^{-1}$. Mineral and matrix properties were assessed using Fourier transform infrared microscopic imaging (FTIRI) in four specific regions of the tibial crosssections (Figure 1): cancellous bone, the endocortical third of the cortex (interior cortical), mid-cortex, and the periosteal third of the cortex (exterior cortical). For each bone area, three different images were recorded. Means and standard deviations for the three images in each bone area were calculated and compared. The values were then averaged for each group. The cross-sections were processed for FTIRI in a blinded fashion and the codes identifying groups not broken until the time of statistical analysis. Background $\left(\mathrm{BaF}_{2}\right.$ window only) and PMMA spectra were collected for each section analyzed for correction of the sample spectral data using ISYS software (Spectral Dimensions, Olney, MD). Spectra were baseline corrected and the PMMA spectral contribution subtracted using ISYS software as previously described in detail [40]. FTIR parameters reviewed in detail elsewhere $[41,42]$ were calculated using ISYS software. The mineral/matrix ratio, which measures bone mineral content (correlated to ash weight) was calculated from the integrated areas of phosphate $\left(916-1180 \mathrm{~cm}^{-1}\right)$ to Amide I (1592-1712 $\left.\mathrm{cm}^{-1}\right)$. The collagen cross-linking network maturity (XLR) was estimated as the 
peak intensity ratio of Amide I subbands at 1660 and $1690 \mathrm{~cm}^{-1}$. The carbonate/phosphate ratio, which reflects the level of carbonate substitution in the hydroxyapatite (HA) crystal was calculated as the integrated area of the $v 2$ carbonate peak $\left(840-892 \mathrm{~cm}^{-1}\right)$ to that of the phosphate. The HA crystallinity, related to mineral crystal size and perfection as determined by $\mathrm{x}$-ray diffraction, was calculated as the phosphate subband $1030 / 1020 \mathrm{~cm}^{-1}$ peak intensity ratio. For each FTIRI parameter, bone heterogeneity was calculated as the full width at half maximum (FWHM) using the pixel histogram distribution (Figure 4A) in both cancellous and cortical bone.

All statistical analyses were performed with SigmaStat (Systat Software Inc, San Jose, CA, USA). One-way ANOVAs were used to compare the treated groups to VEH, and to evaluate dose-responses. Statistical significance was based on the Dunnett's test and defined as $p<0.05$.

\section{Results}

Typical FTIRI images recorded in the endocortical bone region are illustrated for one dog (A) from the control group and one (B) from the group treated with $0.5 \mathrm{mg} / \mathrm{kg} / \mathrm{day}$ of Risedronate (Figure 2). In the cancellous bone mean values for mineral/matrix ratio were higher in all the bisphosphonate groups than in vehicle-treated dogs $(\mathrm{p}<0.05$; Figure 3$)$. For Aln, levels for the Mineral/Matrix ratio were $13 \%(0.2 \mathrm{mg} / \mathrm{kg})$ and $14 \%(1 \mathrm{mg} / \mathrm{kg})$ higher than $\mathrm{Veh}(\mathrm{p}<0.001)$. For Ris, Mineral/Matrix ratios were $11 \%(0.1 \mathrm{mg} / \mathrm{kg}, \mathrm{p}<0.05)$ and $14.5 \%(0.5 \mathrm{mg} / \mathrm{kg}, \mathrm{p}<$ $0.001)$ higher than Veh. No significant differences were found between the dose-equivalents of the two bisphosphonates, or for different doses within each drug. The Mineral/Matrix ratio calculated from the bisphosphonate groups were not significantly different compared to control in the cortical region (data not shown) considered in its whole. When calculated in specific regions of the cortex (Figure 1) the Mineral/Matrix ratio was 6-8\% higher in Ris and Aln than Veh $(\mathrm{p}<0.05)$ in the endocortical third of the cortex. For both mid-cortex and outer cortex no significant differences were observed in the mineral content among groups.

All bisphosphonate-treated groups had a significantly higher collagen crosslink ratio (XLR) compared to vehicle treated controls in all bone areas analyzed, except for the lowest dose of Aln in the outer third of the cortex (Figure 3). XLRs was 10-17\% higher in the cancellous and endocortical regions of the cortex $(\mathrm{P}<0.001)$, but only $7-8 \%$ higher in the mid-cortex $(\mathrm{p}<0.05)$, where bone turnover is slower. The smallest increases were found near the periosteal surface $(4-8 \%, \mathrm{p}<0.05)$. There were no dose-dependent differences in XLR in either Aln or Ris treated groups.

The Carbonate/phosphate ratio and the crystallinity ratio did not show any significant differences in either alendronate- or risedronate-treated dog groups compared to the Veh (Figure 3).

Bone heterogeneity was assessed by the FWHM calculated from the pixel histograms for each individual image as illustrated in Figure 4A. The width of the FWHM reflecting the bone heterogeneity for each FTIRI parameter decreased significantly for the mineral/matrix ratio and crystallinity in both Aln and Ris-treated groups compared to Veh for each of the bone areas analyzed. For the carbonate/phosphate ratio a significant decrease in the FWHM was observed only for Ris 0.1 in cortical bone. Concerning XLR, a decrease in FWHM was noted only for the Aln 0.2 group in cancellous bone compared to the control. FWHM was higher in all groups in cancellous bone compared to cortical bone for each FTIRI parameter $(p<0.001)$. There were no dose dependent differences in bone heterogeneity for any of the IR parameters analyzed in either alendronate or risedronate treated groups, nor were there differences between alendronate and risedronate-treated groups at equi-potent doses. 


\section{Discussion}

FTIRI analysis showed there was significantly higher mineral content and cross-linking maturity in cancellous and cortical bone in canine tibiae of normal dogs treated with Aln or Ris independent of dosage. In terms of mineral content, the previous work based on FTIR analysis to understand the effects of bisphosphonate treatments on bone tissue did not give consistent results. In some studies FTIR spectroscopic parameters of bone treated with bisphosphonates were found to be comparable to control animals as shown in a study of trabecular bone in ovariectomized rats treated with tiludronate [43] as well as in a study of cortical bone from normal dogs treated with high doses of Aln or Ris [33]. Recently, Boskey et al. found by FTIRI analysis that the mineral content in postmenopausal women was significantly increased by Aln treatment in cortical bone but not in cancellous bone [29]. This difference between cancellous and cortical bone modification following bisphosphonate treatment is surprising because one would expect a greater increase from suppressing bone turnover in areas of more rapid remodeling (i.e., cancellous bone) than in areas with preexisting low remodeling (ie cortical bone) [36]. Suppression of bone turnover by bisphosphonates along with increases in the mineral content in both cortical and trabecular bone area is consistent with several studies in ovariectomized rodents and normal dogs [31, $34,44]$. This increase in mineral content can be linked to a significant increase in the structural mechanical properties of bone treated with bisphosphonates in these animal models [32,44, 45]. In this dog model, higher bone mineral content has been found in the vertebrae, ribs and iliac crest from dogs treated with high doses of Aln or Ris, based on pQCT, ash fraction or density fractionation data [33,34], while FTIRI data did not show any mineral or matrix modifications linked with the bisphosphonate treatments. This discrepancy in FTIRI results between the previous and current work is most likely attributable to the examination of whole cortex of bone in the previous study rather than distinct bone areas as was performed in the current work. Although Aln has a higher affinity for bone-like carbonated apatite than risedronate $[46,47]$ and should bind to more sites on the mineral crystals in the normal dog, no significant differences were observed in the bone properties recorded by FTIRI in our study. Differences in binding affinities between Aln and Ris must play a role mainly in how these drugs are retained in the skeleton and influence the persistence of the drug effect.

Durchschlag et al [48] showed through FTIRI analysis of replicate biopsies from risedronatetreated osteoporotic women, that bisphosphonate treatment maintained, but did not increase, the maturity of the collagen cross-link network in cancellous bone. Likewise, Boskey et al [29] did not find any changes in the collagen maturity by FTIRI in healthy postmenopausal women treated with Aln compared to the placebo. These observations contrast with data from several independent studies in human [28] and canine models which found, by biochemical analyses, that treatment with bisphosphonates resulted in collagen maturity changes in bone tissue [30,31]. Our results in the normal canine, coupled with earlier chemical analyses of collagen cross-linking and isomerization in the vertebral bodies of these dogs [30] confirm that collagen maturity is modified by bisphosphonates in both cortical and trabecular bone of normal animals and we show that a part of these modifications can be spatially analyzed by FTIR imaging. The intermolecular cross-linking of collagen is a chemical feature that contributes to the arrangement of collagen molecules in the fibril which provides fibrillar matrices with important mechanical properties for bone tissue. We cannot compare directly the data for the maturity of collagen obtained by FTIRI and biochemical analysis, indeed, the ratio (1660/1690) calculated by FTIRI is an indicator of the environment in which cross-links exist, and these have been correlated with relative amounts of mature and immature enzymatic cross-links [22] whereas the chemical analyses based on methods such as HPLC quantifies the different types of cross-links, including those which are formed by enzymatic and nonenzymatic processes [18], and is likely to be more sensitive. Recently, it was shown the crosslink ratio obtained by FTIRI increases with tissue age and can be correlated with the mechanical 
properties of bone [23]. The present results indicate that the changes in the enzymatic crosslink maturity from bisphosphonate treatment may play a role in the decreased fracture risk associated with these treatments. However, as bone collagen is not only post-translationally modified by enzymatic cross-linking, but also affected by non-enzymatic glycation and $\beta$ isomerization [18] the exact effects of bisphosphonate drugs on bone matrix and their consequences on the mechanical properties is unknown, since all of these modifications may coexist. Recently it was found that the reduction in bone turnover by bisphosphonate treatments increases advanced glycation end-products (AGEs, non-enzymatic cross-links) in bone tissue $[18,30,31,38]$ and this accumulation of AGEs could be associated with reduced tissue-level fracture resistance $[38,49]$.

When bone properties were assessed by FTIRI in cortical bone of the iliac crest (without cancellous bone), no significant changes between control and Aln or Ris groups were detected [33]. On the other hand, as shown in our study, when FTIR parameters are measured in specific cortical areas we observed the endocortical area presents the same bone property modifications as those observed in the cancellous bone. The changes resulting from bisphosphonate treatment are very important in the cancellous area which is altered during osteoporosis [6] and in the endocortical area where the cortical bone loss is accelerated in postmenopausal women [50, 51]. This may help to explain the specific positive effect of these drugs in postmenopausal osteoporosis or osteogenesis imperfecta in children in which there is high turnover in cancellous and endocortical regions $[52,53]$. These results show clearly that bone properties are not uniformly modified by the bisphosphonates and that the FTIRI is a discerning tool to analyze specific areas in very heterogeneous biologic tissues like bone. In studies dealing with efficacy of therapies, some relevant information may be lost when properties of the cancellous and endocortical surface bone parts are coaveraged with those from bulk cortical bone.

We were unable to detect a significant dose dependent effect or differences between the effects of the two different bisphosphonates tested on the observed FTIRI parameters of bone quality. It is possible that the small number of samples analyzed prevented us from detecting a significant effect.

Interestingly, while crystallinity was not significantly modified by bisphosphonates and the mineralization of the bone was only affected in the cancellous and endocortical regions, we found a significant decrease in the distribution of these parameters (heterogeneity) in both cortical and cancellous bone. These data are in agreement with recent FTIRI work on alendronate-treated postmenopausal women [29] where a loss of compositional heterogeneity was associated with antiresorptive treatment, and suggests that the observation of decreased heterogeneity in that study may be related to the antiresoprtive effects of the drug rather than to disease state alone. This effect is not surprising as bone heterogeneity is a product of bone remodeling which is significantly reduced by bisphosphonates. The homogenization of the mineral content and the crystallinity reflects a more static bone tissue in the bisphosphonatetreated normal dog. The decrease is especially significant in cancellous bone. As healthy cancellous bone is characterized by a broad heterogeneity, there is evidence that the homogenization of the cancellous bone affects the mechanical properties of the whole bone $[54,55]$. Although the exact impact of changes in bone heterogeneity on mechanical bone properties has not been analyzed directly, the loss of heterogeneity could be one factor that contributes to increased brittleness of bisphosphonate treated tissues [56]. We propose that the controversy concerning the benefit of long bisphosphonate treatment times compared to shorter treatment times of $<5$ years [57-59] and the unusual shaft fractures in long bone observed in few cases during long term bisphosphonate therapy [60-62] might be explained by excessive bone homogenization. To confirm this hypothesis it will be important in the future to analyze the bone heterogeneity changes with bisphosphonate use as a function of the duration of treatment as it may play a significant role in the prevention of crack initiation and propagation 
processes during cyclic loading and fatigue [63,64]. The bone homogenization observed in this work with bisphosphonate could be correlated to the significant accumulation of micro-damage observed in the vertebra of the same canine model after 1 year of bisphosphonate treatment [32,34]. It thus appears important to consider more carefully bone tissue heterogeneity as a new important bone quality factor when analyzing the effects of therapy duration or dose on bone properties.

This study had several limitations. First, the dogs used in the study were not osteoporotic as ovariectomy alone in dogs does not cause bone loss. Second, the higher dose of drug given to the dogs was 5-6x higher than the clinical dose given to postmenopausal women, on a $\mathrm{mg} / \mathrm{kg}$ basis. Third, even those doses considered to be equivalent to the clinical dose did not take into account species differences in the pharmacokinetics or pharmacodynamic properties, or species differences in bioavailability of the drug.

Nevertheless, the FTIRI data show that both pharmacologic and suprapharmacologic doses of bisphosphonates are associated with similar bone quality modifications in normal canines. Aln and Ris increased the mineral and matrix bone maturity most in higher turnover areas (cancellous and endocortical surfaces) that are more greatly influenced by remodeling suppression. Increased mineralization and enhanced maturity of the organic matrix structure have positive influences on the biomechanical properties of bone which contribute to reduction of fracture risk, but the bone homogenization observed with bisphosphonate use suggests that these drugs also could have negative effects on bone quality. The effectiveness and the safety of the bisphosphonates use are well accepted however a better understanding of the effects of long-term bisphosphonate therapy on bone properties could improve decision in many clinical practice guidelines.

\section{Acknowledgments}

This study was supported by NIH grants R01AR041325, 5R01AR047838, 5T32AR007581, P30AR046121 and a research grant from The Alliance for Better Bone Health (Procter \& Gamble Pharmaceuticals and Sanofi-Aventis). Merck and Co. kindly provided the alendronate. This investigation utilized facilities constructed with support from Research Facilities Improvement Program Grant Number C06RR10601 and C06-RR12538-01 from the NIH National Center for Research Resources.

\section{REFERENCES}

1. Bouxsein ML. Bone quality: Where do we go from here? Osteoporos Int 2003;14(Suppl 5):S118-27. [PubMed: 14504716]

2. Augat $\mathrm{P}$, Schorlemmer $\mathrm{S}$. The role of cortical bone and its microstructure in bone strength. Age Ageing 2006;35(Suppl 2):ii, 27-31.

3. Compston J. Bone quality: What is it and how is it measured? Arq Bras Endocrinol Metabol 2006;50:579-85. [PubMed: 17117283]

4. Bouxsein ML, Karasik D. Bone geometry and skeletal fragility. Curr Osteoporos Rep 2006;4:49-56. [PubMed: 16822403]

5. Viguet-Carrin S, Garnero P, Delmas PD. The role of collagen in bone strength. Osteoporos Int 2006;17:319-36. [PubMed: 16341622]

6. Chavassieux P, Seeman E, Delmas PD. Insights into material and structural basis of bone fragility from diseases associated with fractures: How determinants of the biomechanical properties of bone are compromised by disease. Endocr Rev 2007;28:151-64. [PubMed: 17200084]

7. Ruppel ME, Miller LM, Burr DB. The effect of the microscopic and nanoscale structure on bone fragility. Osteoporos Int 2008;19:1251-65. [PubMed: 18317862]

8. Black DM, Cummings SR, Karpf DB, Cauley JA, Thompson DE, Nevitt MC, et al. Randomised trial of effect of alendronate on risk of fracture in women with existing vertebral fractures. fracture intervention trial research group. Lancet 1996;348:1535-41. [PubMed: 8950879] 
9. Cummings SR, Black DM, Thompson DE, Applegate WB, Barrett-Connor E, Musliner TA, et al. Effect of alendronate on risk of fracture in women with low bone density but without vertebral fractures: Results from the fracture intervention trial. JAMA 1998;280:2077-82. [PubMed: 9875874]

10. Harris ST, Watts NB, Genant HK, McKeever CD, Hangartner T, Keller M, et al. Effects of risedronate treatment on vertebral and nonvertebral fractures in women with postmenopausal osteoporosis: A randomized controlled trial. vertebral efficacy with risedronate therapy (VERT) study group. JAMA 1999;282:1344-52. [PubMed: 10527181]

11. Delmas PD. Treatment of postmenopausal osteoporosis. Lancet 2002;359:2018-26. [PubMed: 12076571]

12. Hosking D, Adami S, Felsenberg D, Andia JC, Valimaki M, Benhamou L, et al. Comparison of change in bone resorption and bone mineral density with once-weekly alendronate and daily risedronate: A randomised, placebo-controlled study. Curr Med Res Opin 2003;19:383-94. [PubMed: 13678475]

13. Drake MT, Clarke BL, Khosla S. Bisphosphonates: Mechanism of action and role in clinical practice. Mayo Clin Proc 2008;83:1032-45. [PubMed: 18775204]

14. Cohen A, Shane E. Treatment of premenopausal women with low bone mineral density. Curr Osteoporos Rep 2008;6:39-46. [PubMed: 18430399]

15. Coleman RE. Risks and benefits of bisphosphonates. Br J Cancer 2008;98:1736-40. [PubMed: 18506174]

16. Delmas PD, Seeman E. Changes in bone mineral density explain little of the reduction in vertebral or nonvertebral fracture risk with anti-resorptive therapy. Bone 2004;34:599-604. [PubMed: 15050889]

17. Haguenauer D, Welch V, Shea B, Tugwell P, Adachi JD, Wells G. Fluoride for the treatment of postmenopausal osteoporotic fractures: A meta-analysis. Osteoporos Int 2000;11:727-38. [PubMed: 11148800]

18. Leeming DJ, Henriksen K, Byrjalsen I, Qvist P, Madsen SH, Garnero P, et al. Is bone quality associated with collagen age? Osteoporos Int 2009;20:1461-70. [PubMed: 19330423]

19. Knott L, Bailey AJ. Collagen cross-links in mineralizing tissues: A review of their chemistry, function, and clinical relevance. Bone 1998;22:181-7. [PubMed: 9514209]

20. Currey JD, Brear K, Zioupos P. The effects of ageing and changes in mineral content in degrading the toughness of human femora. J Biomech 1996;29:257-60. [PubMed: 8849821]

21. Bailey AJ, Sims TJ, Ebbesen EN, Mansell JP, Thomsen JS, Mosekilde L. Age-related changes in the biochemical properties of human cancellous bone collagen: Relationship to bone strength. Calcif Tissue Int 1999;65:203-10. [PubMed: 10441651]

22. Paschalis EP, Verdelis K, Doty SB, Boskey AL, Mendelsohn R, Yamauchi M. Spectroscopic characterization of collagen cross-links in bone. J Bone Miner Res 2001;16:1821-8. [PubMed: 11585346]

23. Gourion-Arsiquaud S, Burket J, Havill L, Dicarlo E, Doty S, Mendelsohn R, van der Meulen M, et al. Spatial variation in osteonal bone properties relative to tissue and animal age. J Bone Miner Res 2009;24:1271-81. [PubMed: 19210217]

24. Siegmund T, Allen MR, Burr DB. Failure of mineralized collagen fibrils: Modeling the role of collagen cross-linking. J Biomech 2008;41:1427-35. [PubMed: 18406410]

25. Liberman UA, Weiss SR, Broll J, Minne HW, Quan H, Bell NH, et al. Effect of oral alendronate on bone mineral density and the incidence of fractures in postmenopausal osteoporosis. the alendronate phase III osteoporosis treatment study group. N Engl J Med 1995;333:1437-43. [PubMed: 7477143]

26. Bone HG, Hosking D, Devogelaer JP, Tucci JR, Emkey RD, Tonino RP, et al. Ten years' experience with alendronate for osteoporosis in postmenopausal women. N Engl J Med 2004;350:1189-99. [PubMed: 15028823]

27. Breuil V, Cosman F, Stein L, Horbert W, Nieves J, Shen V, et al. Human osteoclast formation and activity in vitro: Effects of alendronate. J Bone Miner Res 1998;13:1721-9. [PubMed: 9797481]

28. Byrjalsen I, Leeming DJ, Qvist P, Christiansen C, Karsdal MA. Bone turnover and bone collagen maturation in osteoporosis: Effects of antiresorptive therapies. Osteoporos Int 2008;19:339-48. [PubMed: 17846859]

29. Boskey AL, Spevak L, Weinstein RS. Spectroscopic markers of bone quality in alendronate-treated postmenopausal women. Osteoporos Int 2009;20:793-800. [PubMed: 18769963] 
30. Allen MR, Gineyts E, Leeming DJ, Burr DB, Delmas PD. Bisphosphonates alter trabecular bone collagen cross-linking and isomerization in beagle dog vertebra. Osteoporos Int 2008;19:329-37. [PubMed: 18094911]

31. Saito M, Mori S, Mashiba T, Komatsubara S, Marumo K. Collagen maturity, glycation inducedpentosidine, and mineralization are increased following 3-year treatment with incadronate in dogs. Osteoporos Int 2008;19:1343-54. [PubMed: 18373056]

32. Mashiba T, Turner CH, Hirano T, Forwood MR, Johnston CC, Burr DB. Effects of suppressed bone turnover by bisphosphonates on microdamage accumulation and biomechanical properties in clinically relevant skeletal sites in beagles. Bone 2001;28:524-31. [PubMed: 11344052]

33. Burr DB, Miller L, Grynpas M, Li J, Boyde A, Mashiba T, et al. Tissue mineralization is increased following 1-year treatment with high doses of bisphosphonates in dogs. Bone 2003;33:960-9. [PubMed: 14678856]

34. Allen MR, Iwata K, Phipps R, Burr DB. Alterations in canine vertebral bone turnover, microdamage accumulation, and biomechanical properties following 1-year treatment with clinical treatment doses of risedronate or alendronate. Bone 2006;39:872-9. [PubMed: 16765660]

35. Mashiba T, Hirano T, Turner CH, Forwood MR, Johnston CC, Burr DB. Suppressed bone turnover by bisphosphonates increases microdamage accumulation and reduces some biomechanical properties in dog rib. J Bone Miner Res 2000;15:613-20. [PubMed: 10780852]

36. Mashiba T, Turner CH, Hirano T, Forwood MR, Jacob DS, Johnston CC, et al. Effects of high-dose etidronate treatment on microdamage accumulation and biomechanical properties in beagle bone before occurrence of spontaneous fractures. Bone 2001;29:271-8. [PubMed: 11557372]

37. Komatsubara S, Mori S, Mashiba T, Ito M, Li J, Kaji Y, et al. Long-term treatment of incadronate disodium accumulates microdamage but improves the trabecular bone microarchitecture in dog vertebra. J Bone Miner Res 2003;18:512-20. [PubMed: 12619936]

38. Tang SY, Allen MR, Phipps R, Burr DB, Vashishth D. Changes in non-enzymatic glycation and its association with altered mechanical properties following 1-year treatment with risedronate or alendronate. Osteoporos Int 2009;20:887-94. [PubMed: 18850239]

39. Zoehrer R, Roschger P, Paschalis EP, Hofstaetter JG, Durchschlag E, Fratzl P, et al. Effects of 3- and 5 -year treatment with risedronate on bone mineralization density distribution in triple biopsies of the iliac crest in postmenopausal women. J Bone Miner Res 2006;21:1106-12. [PubMed: 16813531]

40. Gourion-Arsiquaud S, West PA, Boskey AL. Fourier transform-infrared microspectroscopy and microscopic imaging. Methods Mol Biol 2008;455:293-303. [PubMed: 18463826]

41. Boskey AL, Mendelsohn R. Infrared spectroscopic characterization of mineralized tissues. Vib Spectrosc 2005;38:107-14. [PubMed: 16691288]

42. Gourion-Arsiquaud S, Boskey AL. Fourier transform infrared and Raman microspectroscopy and microscopic imaging of bone. Current Opinion in Orthopedics 2007;18:499.

43. Bohic S, Rey C, Legrand A, Sfihi H, Rohanizadeh R, Martel C, et al. Characterization of the trabecular rat bone mineral: Effect of ovariectomy and bisphosphonate treatment. Bone 2000;26:341-8. [PubMed: 10719276]

44. Bourrin S, Ammann P, Bonjour JP, Rizzoli R. Recovery of proximal tibia bone mineral density and strength, but not cancellous bone architecture, after long-term bisphosphonate or selective estrogen receptor modulator therapy in aged rats. Bone 2002;30:195-200. [PubMed: 11792585]

45. Day JS, Ding M, Bednarz P, van der Linden JC, Mashiba T, Hirano T, et al. Bisphosphonate treatment affects trabecular bone apparent modulus through microarchitecture rather than matrix properties. $\mathrm{J}$ Orthop Res 2004;22:465-71. [PubMed: 15099622]

46. Nancollas GH, Tang R, Phipps RJ, Henneman Z, Gulde S, Wu W, et al. Novel insights into actions of bisphosphonates on bone: differences in interactions with hydroxyapatite. Bone 2006;38:617-27. [PubMed: 16046206]

47. Henneman ZJ, Nancollas GH, Ebetino FH, Russell RG, Phipps RJ. Bisphosphonate binding affinity as assessed by inhibition of carbonated apatite dissolution in vitro. J Biomed Mater Res A 2008;84:993-1000. [PubMed: 17907244]

48. Durchschlag E, Paschalis EP, Zoehrer R, Roschger P, Fratzl P, Recker R, et al. Bone material properties in trabecular bone from human iliac crest biopsies after 3- and 5-year treatment with risedronate. J Bone Miner Res 2006;21:1581-90. [PubMed: 16995813] 
49. Saito M, Fujii K, Mori Y, Marumo K. Role of collagen enzymatic and glycation induced cross-links as a determinant of bone quality in spontaneously diabetic WBN/Kob rats. Osteoporos Int 2006;17:1514-23. [PubMed: 16770520]

50. Frost HM. On the estrogen-bone relationship and postmenopausal bone loss: A new model. J Bone Miner Res 1999;14:1473-7. [PubMed: 10469274]

51. Szulc P, Seeman E, Duboeuf F, Sornay-Rendu E, Delmas PD. Bone fragility: Failure of periosteal apposition to compensate for increased endocortical resorption in postmenopausal women. J Bone Miner Res 2006;21:1856-63. [PubMed: 17002580]

52. Shaw NJ, Bishop NJ. Bisphosphonate treatment of bone disease. Arch Dis Child 2005;90:494-9. [PubMed: 15851432]

53. Speiser PW, Clarson CL, Eugster EA, Kemp SF, Radovick S, Rogol AD, et al. Bisphosphonate treatment of pediatric bone disease. Pediatr Endocrinol Rev 2005;3:87-96. [PubMed: 16361982]

54. Keaveny TM, Hayes WC. A 20-year perspective on the mechanical properties of trabecular bone. J Biomech Eng 1993;115:534-42. [PubMed: 8302037]

55. Renders GA, Mulder L, Langenbach GE, van Ruijven LJ, van Eijden TM. Biomechanical effect of mineral heterogeneity in trabecular bone. J Biomech 2008;41:2793-98. [PubMed: 18722619]

56. Misof BM, Roschger P, Baldini T, Raggio CL, Zraick V, Root L, et al. Differential effects of alendronate treatment on bone from growing osteogenesis imperfecta and wild-type mouse. Bone 2005;36:150-8. [PubMed: 15664013]

57. Black DM, Schwartz AV, Ensrud KE, Cauley JA, Levis S, Quandt SA, et al. Effects of continuing or stopping alendronate after 5 years of treatment: The fracture intervention trial long-term extension (FLEX): A randomized trial. JAMA 2006;296:2927-38. [PubMed: 17190893]

58. Sebba A. Osteoporosis: How long should we treat? Curr Opin Endocrinol Diabetes Obes 2008;15:502-7. [PubMed: 18971678]

59. Geusens P. Bisphosphonates for postmenopausal osteoporosis: Determining duration of treatment. Curr Osteoporos Rep 2009;7:12-7. [PubMed: 19239824]

60. Lenart BA, Lorich DG, Lane JM. Atypical fractures of the femoral diaphysis in postmenopausal women taking alendronate. N Engl J Med 2008;358:1304-6. [PubMed: 18354114]

61. Lenart BA, Neviaser AS, Lyman S, Chang CC, Edobor-Osula F, Steele B, et al. Association of lowenergy femoral fractures with prolonged bisphosphonate use: A case control study. Osteoporos Int 2009;20:1353-62. [PubMed: 19066707]

62. Odvina CV, Levy S, Rao S, Zerwekh JE, Sudhaker Rao D. Unusual mid-shaft fractures during long term bisphosphonate therapy. Clin Endocrinol (Oxf). 2009

63. Schaffler MB. Role of bone turnover in microdamage. Osteoporos Int 2003;14(Suppl 5):S73, 7. discussion S77-80. [PubMed: 14504710]

64. Kosmopoulos V, Schizas C, Keller TS. Modeling the onset and propagation of trabecular bone microdamage during low-cycle fatigue. J Biomech 2008;41:515-22. [PubMed: 18076887] 


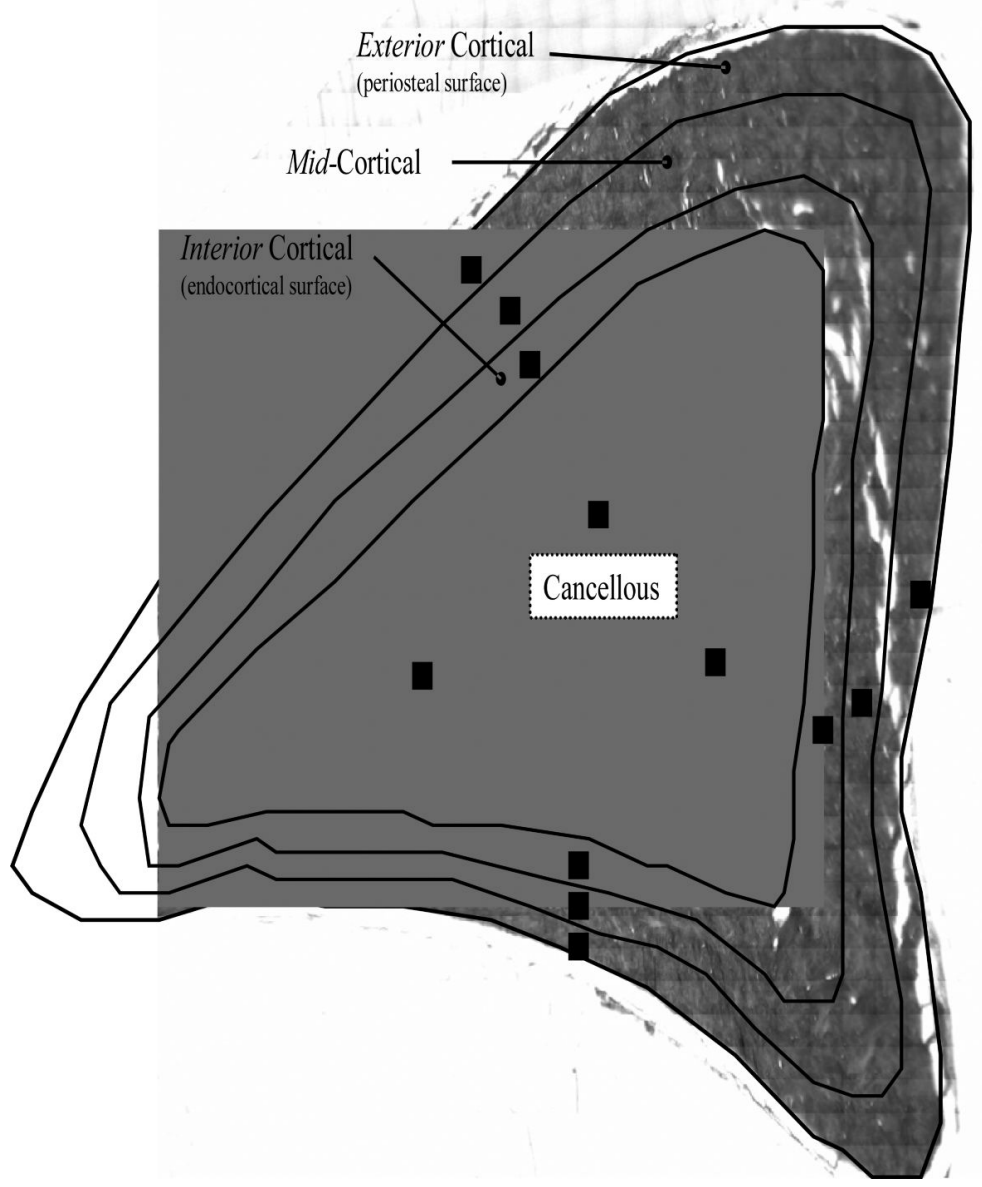

Figure 1.

For each dog cross-section 12 images (black squares) recorded by FTIR imaging were analyzed from 4 different bone areas; 3 in cancellous, 3 in the inner third of the cortex, 3 in mid-cortex, and 3 in the outer third of the cortex. 
Figure 2. 1 pixel $=6.25 \times 6.25 \mu \mathrm{m}$.
Mineral/Matrix ratio

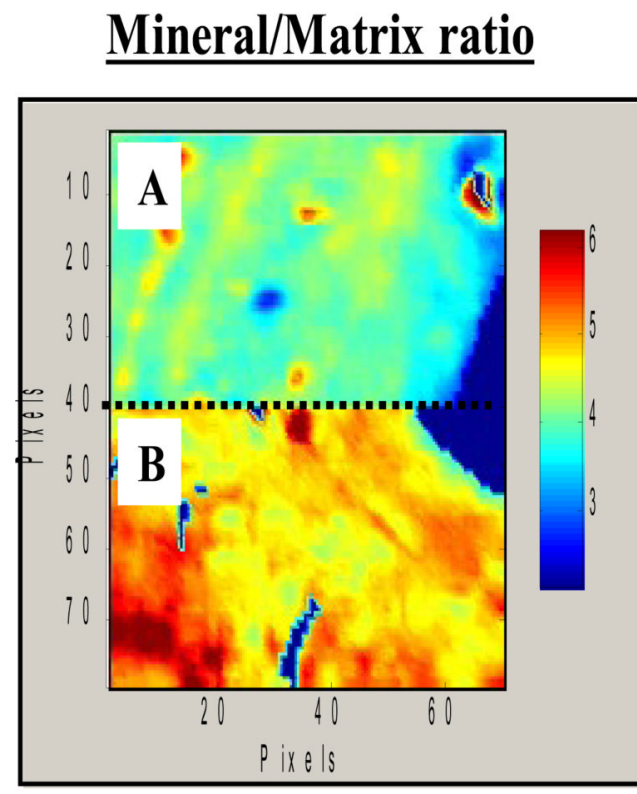

Carbonate/Phosphate ratio

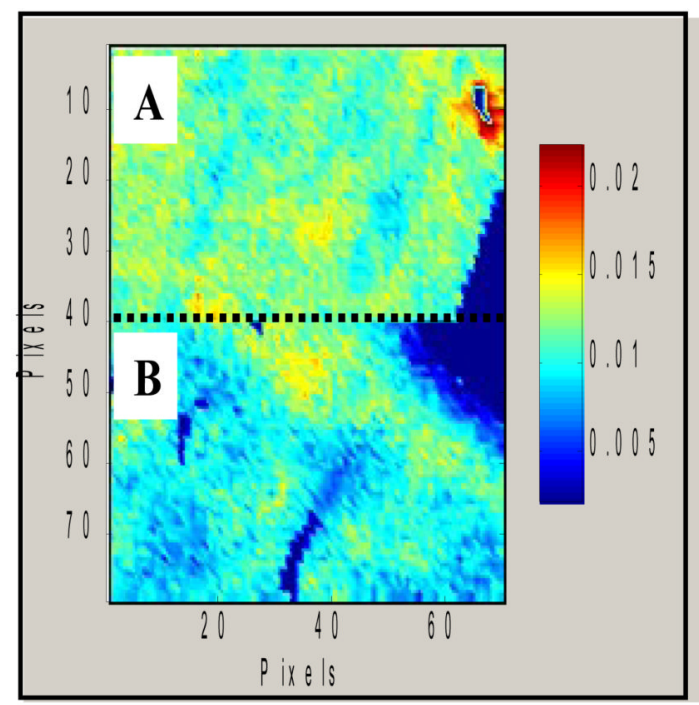

$\underline{\operatorname{XLR}\left(1660 / 1690 \mathrm{~cm}^{-1}\right)}$

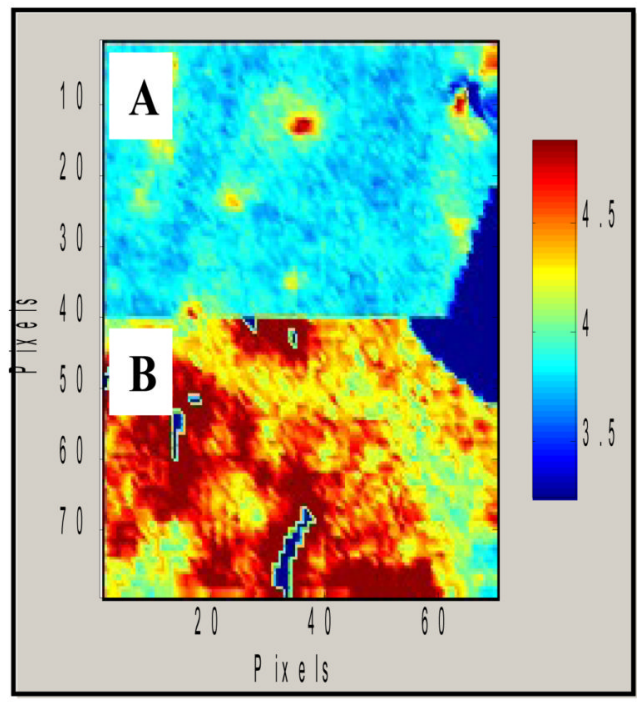

Crystallinity $\left(1030 / 1020 \mathrm{~cm}^{-1}\right)$

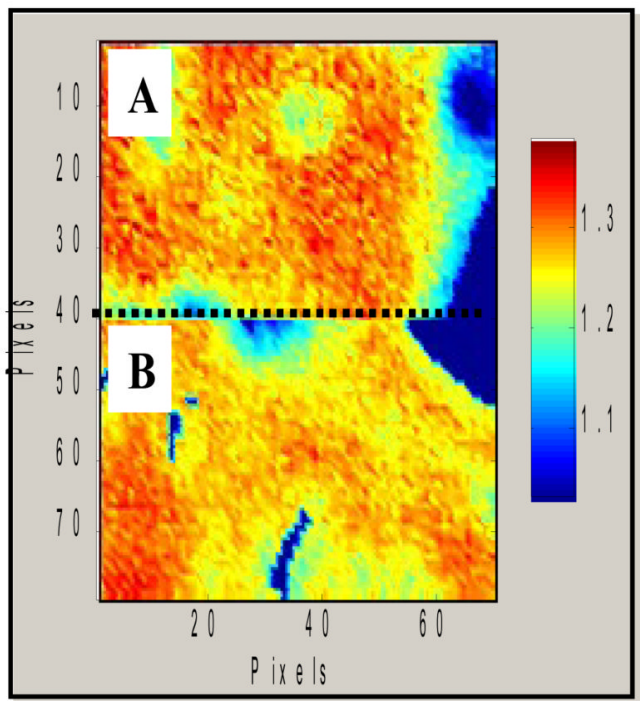

Typical Infrared images for the Mineral/Matrix ratio, cross-link maturity (XLR), Carbonate/ Phosphate ratio and crystallinity ratio recorded from the endocortical third of the cortex in the control group (A) and the $0.5 \mathrm{mg} / \mathrm{kg} /$ day risedronate-treated group (B). Note in these figures 
Mineral/Matrix ratio

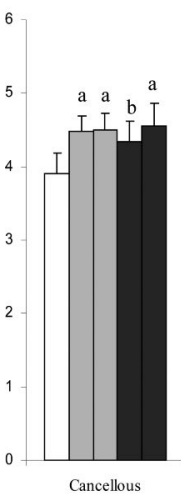

Cancellous

Cross-link ratio

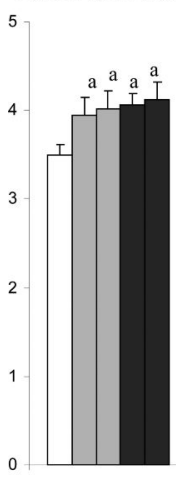

Cancellous
Veh Aln $02 \square$ Aln 1 Ris 0.1 Ris 0.5

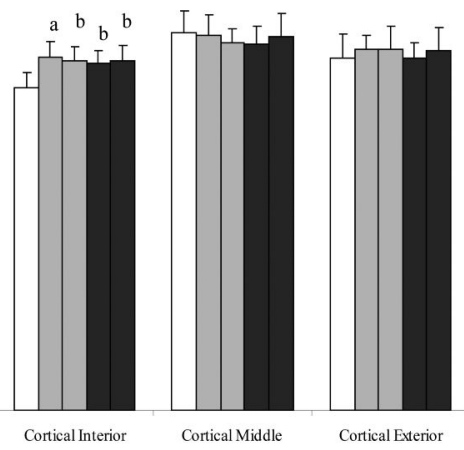

$\square$ Veh $\square$ Ann $0.2 \square$ An 1 घ Ris 0.1 Ris 0.5

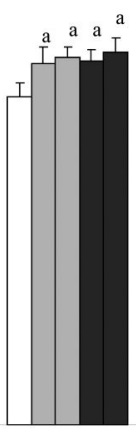

Cortical Interior

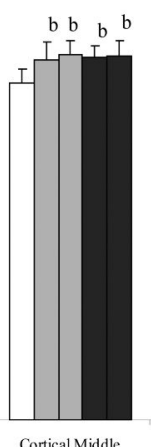

Cortical Middle

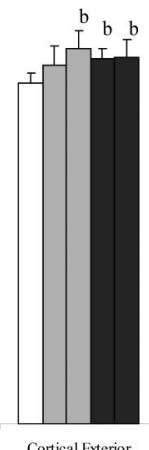

Cortical Exterior

\section{Carbonate/Phosphate ratio}

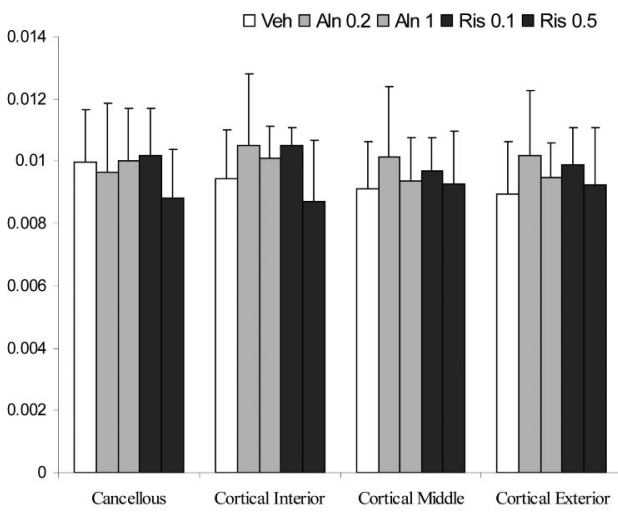

Crystallinity

$$
1.4
$$

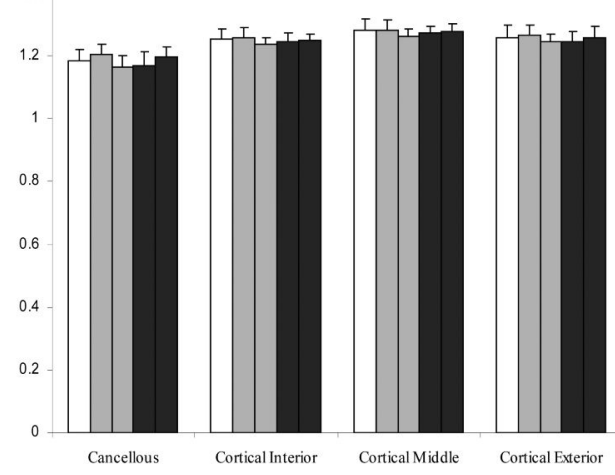

Figure 3.

Changes in mineral and matrix bone properties with anti-remodeling agents calculated by FTIR at different bone locations. Data presented as mean \pm SD. (a) $p<0.001$ and (b) $p<0.05$ versus vehicle within each region. 


\section{A}

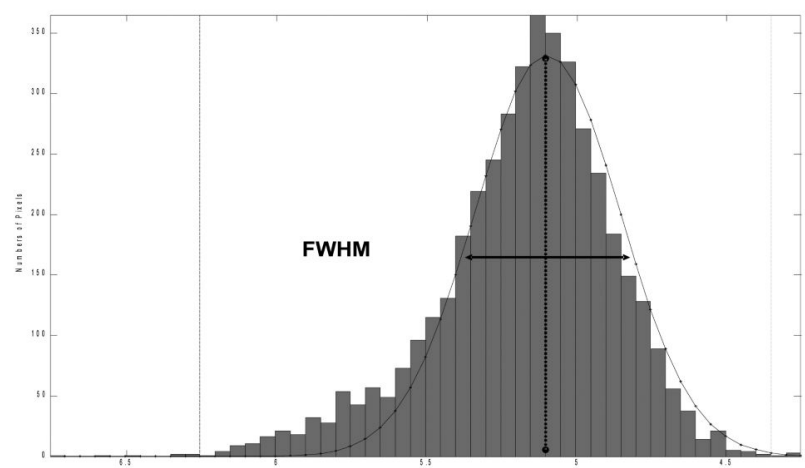

B

Mineral/Matrix ratio

$\square$ Veh $\square$ Aln $0.2 \square$ An $1 \square$ Ris $0.1 \square$ Ris 0.5

Figure 4.
Carbonate/Phosphate ratio

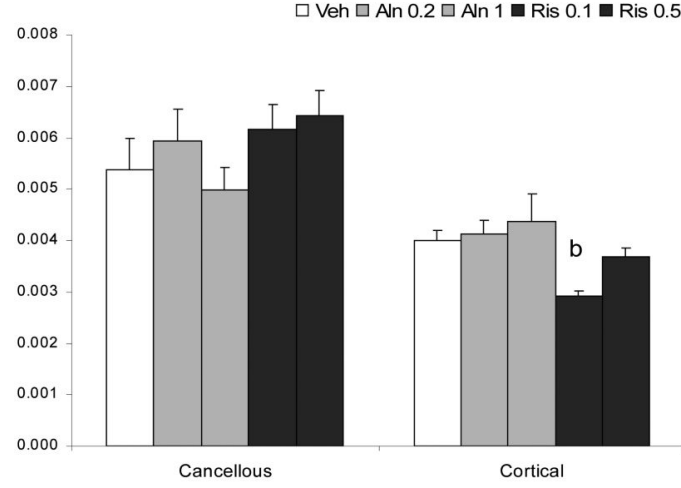

\section{Crystallinity}

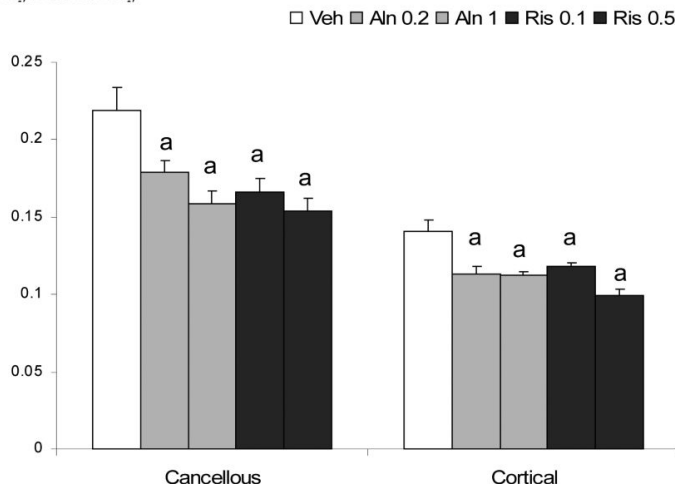

Bone heterogeneity was assessed by the FWHM of pixel distribution (A) from each FTIR image. FWHM was calculated for each FTIR parameter in both cancellous and cortical bone for each group (B). Data presented as mean \pm SD. (a) $p<0.001$ and (b) $p<0.05$ versus vehicle. 